\title{
The Effect of Retrofit Technologies on Formaldehyde Emissions from a Large Bore Natural Gas Engine
}

\author{
Daniel B. Olsen*, Bryan D. Willson \\ Engines \& Energy Conversion Laboratory, Department of Mechanical Engineering, \\ Colorado State University, Fort Collins, Colorado, USA \\ E-mail: *daniel.olsen@colostate.edu \\ Received June 23, 2011; revised July 28, 2011; accepted August 10, 2011
}

\begin{abstract}
Formaldehyde is an air toxic that is typically emitted from natural gas-fired internal combustion engines as a product of incomplete combustion. The United States Environmental Protection Agency (EPA) regulates air toxic emissions, including formaldehyde, from stationary reciprocating internal combustion engines. National air toxic standards are required under the 1990 Clean Air Act Amendments. This work investigates the effect that hardware modifications, or retrofit technologies, have on formaldehyde emissions from a large bore natural gas engine. The test engine is a Cooper-Bessemer GMV-4TF two stroke cycle engine with a 14" $(35.6 \mathrm{~cm})$ bore and a 14” $(35.6 \mathrm{~cm})$ stroke. The impact of modifications to the fuel injection and ignition systems are investigated. Data analysis and discussion is performed with reference to possible formaldehyde formation mechanisms and in-cylinder phenomena. The results show that high pressure fuel injection (HPFI) and precombustion chamber (PCC) ignition significantly reduce formaldehyde emissions.
\end{abstract}

Keywords: Formaldehyde, Natural Gas, Fuel Injection, Precombustion Chamber, Large Bore

\section{Introduction}

Formaldehyde is a toxic emission that is specifically troublesome for natural gas engines because it is a primary combustion intermediate. It falls into a regulated group of pollutants called HAPs (Hazardous Air Pollutants). HAPs do not include criteria pollutants, carbon monoxide (CO), oxides of nitrogen $\left(\mathrm{NO}_{\mathrm{x}}\right)$, or total hydrocarbons (THC). They include a variety of aldehydes, volatile organic compounds, semi-volatile organic compounds, sulfur compounds, and metals. The United States Environmental Protection Agency (EPA) issues toxic regulations for oil and gas production, as declared by the 1990 Clean Air Act Amendments. It has been well established that the only HAP present in the exhaust of large bore natural gas engines in quantities of current regulatory significance is formaldehyde [1]. The implications of air toxic regulations to large bore natural gas engines used in gas compression and power generation are well documented [2-4].

The mechanisms of formation for $\mathrm{CO}, \mathrm{NO}_{\mathrm{X}}$, and THC have been studied extensively for a wide range of engine designs and fuels. In contrast, relatively little is known about the mechanisms through which engine-out formaldehyde is formed. Research in this area is in its infancy relative to that of criteria pollutants. A thorough understanding of formaldehyde formation will be beneficial as the natural gas industry responds to EPA air toxic regulations and future revisions to these regulations.

This work addresses the dependency of stack formaldehyde emissions from a large bore natural gas engine on hardware modifications. The level of insight into in-cylinder emissions formation mechanisms one can obtain from stack emissions measurements is limited. However, it is still useful and instructive to analyze the results, particularly in the context of proposed engine-out formaldehyde formation mechanisms. Based on earlier work by the authors and co-workers $[5,6]$ the following formaldehyde formation mechanisms may be important:

1) Formaldehyde produced during piston and end-gas compression and protected from flame propagation in regions such as crevice volumes and wall quench zones emerges during expansion.

2) Unburned hydrocarbons emitted during expansion from regions protected from flame propagation are subsequently oxidized to formaldehyde.

3) Flame is quenched due to a cold wall, mixing with cooler gas, or volume expansion; combustion reactions are frozen and significant quantities of combustion intermedi- 
ates, including formaldehyde, are produced.

\section{Experimental Equipment and Conditions}

\subsection{Engine Testbed}

The test engine is a Cooper-Bessemer GMV-4TF. A photograph of the engine is shown in Figure 1. The GMV-4TF is a 4 cylinder two-stroke cycle, 14 " $(35.6 \mathrm{~cm})$ bore, 14 ” (35.6 cm) stroke, natural gas fired engine. The GMV-4TF has a sea level brake power rating of 440 bhp (330 kW) at 300 rpm. The GMV-4TF nominally uses electro-hydraulic gas admission valves, which deliver fuel to each cylinder individually at an injection pressure of about 45 psig (310 $\mathrm{kPag}$ ). Actuation is performed by pressurized hydraulic fluid on the back of the poppet valve stem. The pressurized hydraulic fluid is controlled electronically by a solenoid valve. The engine is nominally operated with single strike spark ignition.

A combustion analysis system with piezoelectric pressure transducers uses cylinder pressure profiles to calculate peak pressure, location of peak pressure, misfire frequency, and combustion stability parameters. A computer controlled water brake dynamometer is employed for precise load control. A turbocharger simulation system controls intake and exhaust manifold pressures, allowing the simulation of a wide range of engine "breathing" configurations. The turbocharger simulation system is composed of two main components, a super charger (Roots blower) to pressurize the intake air and a motorized, computer controlled backpressure valve. The facility also has the ability to control jacket water temperature, air manifold temperature, and air manifold relative humidity. A Rosemount five-gas analyzer is used for measuring $\mathrm{NO}_{\mathrm{X}}, \mathrm{CO}, \mathrm{THC}, \mathrm{O}_{2}$, and $\mathrm{CO}_{2}$, and a Nicolet Fourier Transform Infrared (FTIR) Spectrometer for examination of a wide range of species including formaldehyde, acetaldehyde, and acrolein.

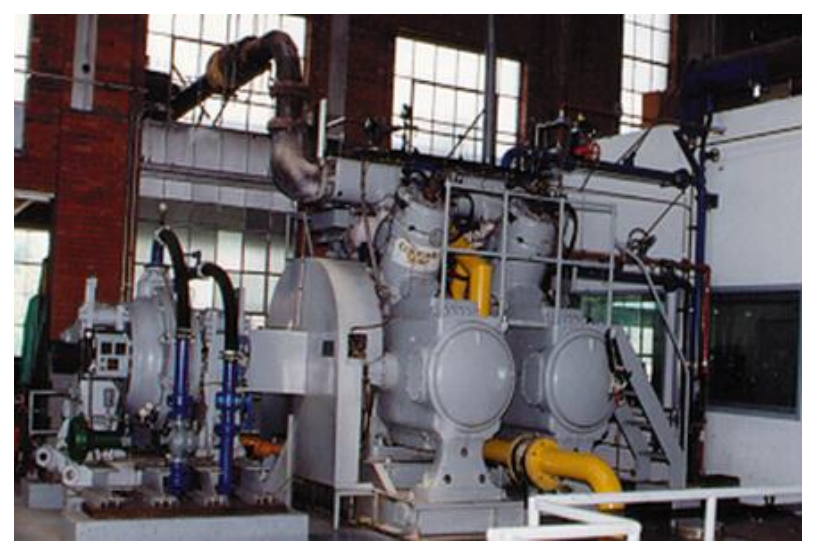

Figure 1. The cooper bessemer GMV-4TF large bore natural gas engine.
Table 1. Nominal operating conditions for the GMV-4TF. HPFI and PCC technologies impact mixing and combustion in the cylinder.

\begin{tabular}{ll}
\hline ENGINE & $\begin{array}{l}\text { NOMINAL VALUE OR } \\
\text { SPECIFICAION }\end{array}$ \\
\hline Brake Power & $440 \mathrm{hp}(330 \mathrm{~kW})$ \\
Dynamometer Torque & $7730 \mathrm{ft}-\mathrm{lb}(10.5 \mathrm{kN}-\mathrm{m})$ \\
Engine Speed & $300 \mathrm{rpm}(5 \mathrm{~Hz})$ \\
Ignition Timing & $10^{\circ} \mathrm{BTDC}$ \\
Intake Manifold Pressure & $7.5^{\prime} \mathrm{Hg}(25 \mathrm{kPag})$ \\
Engine Pressure Drop & $2.5^{\prime} \mathrm{Hg}(8.5 \mathrm{kPa})$ \\
Overall A/F Ratio & 43 \\
Trapped A/F Ratio & 22 \\
Average Peak Pressure & $505 \mathrm{psia}(3.48 \mathrm{MPa})$ \\
Intake Manifold Temperature & $110^{\circ}(317 \mathrm{~K})$ \\
Intake Humidity Ratio & $0.028 \mathrm{~kg} \mathrm{H} \mathrm{O} / \mathrm{kg}$ dry air \\
Jacket Water Temperature & $160^{\circ}(340 \mathrm{~K})$ \\
Ignition & Single Strike, Spark \\
Fuel Delivery & $\begin{array}{l}\text { Direct Injection, Electro-hydraulic, } \\
45 \mathrm{psig}(310 \mathrm{kPag})\end{array}$ \\
\hline
\end{tabular}

Variations in engine operating parameters and changes to engine hardware configuration is performed relative to the nominal operating conditions and hardware configuration. The nominal operating conditions and hardware configuration are summarized in Table $\mathbf{1}$.

\subsection{Retrofit Technology}

Retrofit technologies employed in this study are high pressure fuel injection (HPFI), multi-strike (MS) ignition, and precombustion chamber (PCC) ignition. The HPFI system is produced by Woodward Governor and Dresser-Rand Enginuity. The PCC is made by Diesel Supply Company. The multi-strike (MS) ignition system is made by Altronic Inc. Turbocharging is another retrofit technology that increases the trapped air/fuel ratio. The effect of trapped air/fuel ratio on formaldehyde emissions was evaluated in previous work [7]. Turbocharging is generally implemented to reduce $\mathrm{NO}_{\mathrm{X}}$ emissions by increasing the trapped air/fuel ratio. Unfortunately, this significantly increases emissions of formaldehyde and other products of partial combustion.

In both cases mixing and combustion is enhanced by a gas jet that flows into the cylinder and creates turbulence. In HPFI (512 psia/3.5 MPa) an over-expanded gas fuel jet enters the cylinder as a high energy density sonic jet. The specific hardware configuration is described in other work 
$[8,9]$. After exiting the nozzle the jet subsequently expands to supersonic velocities, followed by a barrel shock and other compressible flow structures [10]. There are two mechanisms by which combustion characteristics are altered, enhanced mixing and increased turbulence. They can impact combustion in different ways that are not easily separated.

Data for three different fuel injection poppet valves are presented in this paper. The geometries of these valves are described in elsewhere [11]. The fuel injection pressures for the low pressure mechanical, low pressure electro-hydraulic, and high pressure electro-hydraulic are 25, 45, and 500 psig (0.17, 0.31, and 3.4 MPag), respectively. Besides the difference in injection pressure, another important difference between the valves is the lift profile. The low pressure mechanical valve is cam actuated and the profile resembles a half sinusoid. The electro-hydraulically actuated valves have lift profiles that approximate square waves. The injection pressure for the high pressure electro-hydraulic valve is more than an order of magnitude greater than the low pressure mechanical and low pressure electro- hydraulic valves, which increases the fuel jet energy density (kinetic energy per unit volume) as the gas enters the cylinder.

The fuel jet energy per unit volume at the valve exit is plotted in Figure $\mathbf{2}$ for the three different valves, and three different high pressure electro-hydraulic cases. These calculations are made with standard compressible flow analysis assuming isentropic flow and applying a loss coefficient. The jet exit kinetic energy per unit volume is approximately 10X higher for the $0.64 \mathrm{~mm}$ lift $3.4 \mathrm{MPag}$ high pressure electro-hydraulic case than for the low pressure electro-hydraulic and low pressure mechanical cases. The gas does not enter the cylinder at a higher speed because it is choked at the exit in all cases, with the exception of the last part of the low pressure mechanical valve injection

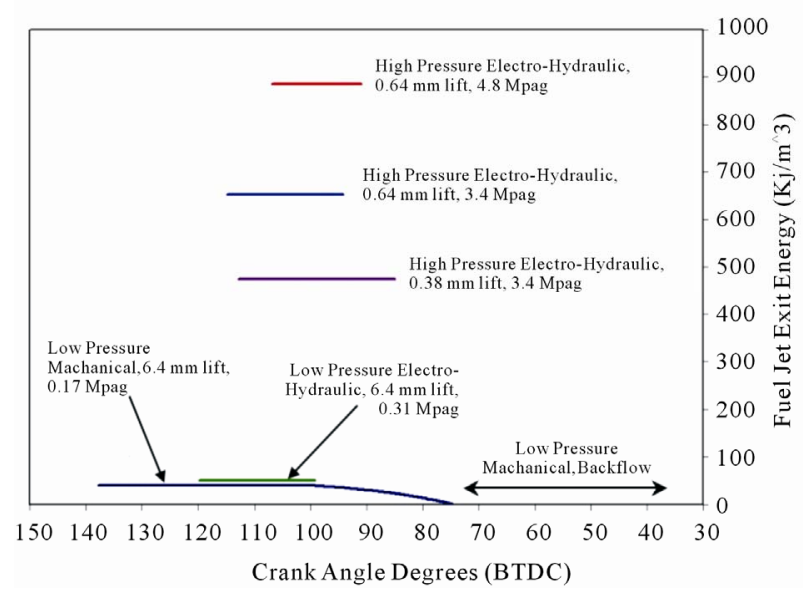

Figure 2. Fuel jet exit kinetic energy per unit volume at valve exit plane. when cylinder pressure is rising. However, the density of the jet entering the cylinder is much higher for the high pressure electro-mechanical case. The frontal area of the exiting jet for the $0.64 \mathrm{~mm}$ lift 3.4 MPag high pressure electro-hydraulic case is approximately $1 / 12$ th that of the low pressure mechanical case. The dramatic increase in fuel jet kinetic energy per unit volume enhances fuel and air mixing and may increase the level of turbulence in the cylinder during combustion. It is difficult to determine whether the turbulence induced by fuel injection is present during combustion, since combustion occurs later in the cycle. Turbulence and mixing are two different, interrelated effects that can affect combustion in different ways. It is also possible that the acoustics in the cylinder play an important role. With a pressure ratio exceeding 34/1, strong shock waves are generated when the high pressure valve is actuated. These shock waves and their reflected shock waves have gas displacements associated with them that could enhance mixing as well.

In PCC ignition a stoichiometric or rich $\mathrm{A} / \mathrm{F}$ mixture is ignited with a spark plug in the PCC. A screw-in PCC is utilized in this work. The hardware and operational details are described elsewhere [12,13]. After ignition and pressure rise in the PCC a jet of burning fuel and air enters the cylinder, providing a distributed ignition source and simultaneously creating turbulence and enhancing mixing. Enhanced mixing, a distributed ignition source, and ignition sources that begin as turbulent flames, as opposed to spark ignition where the combustion is initiated as a laminar flame, simultaneously augment combustion.

\section{Test Results}

Figure 3 shows brake specific formaldehyde emissions vs. boost, or air manifold pressure, for three different fuel injectors. Data for the low pressure mechanical valve and low pressure electro-hydraulic valve are relatively close together. However, a significant decrease in formaldehyde emissions is observed for the high pressure electro-hydraulic valve data at every boost level, with the exception of the low boost point. The decrease in formaldehyde is attributed to an increase in the mixing of fuel and air, or charge homogeneity, in the cylinder. It is likely that the increase in mixing decreases the level of incomplete combustion in the cylinder, particularly in quench zones (Mechanism \#3 discussed above). Given this mechanism, the anticipated parallel effect would be the simultaneous reduction in THC emissions, since they too are 'formed' in quench zones for lean combustion.

Figure 4 shows the expected decrease in THC emissions for the high pressure electro-hydraulic valve. The THC trends are very similar those observed in the formaldehyde data, except there is a significant difference between the 


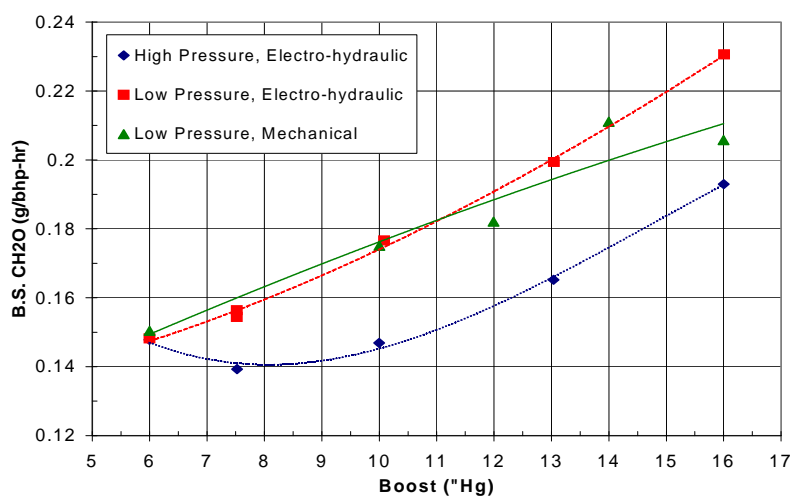

Figure 3. Formaldehyde emissions vs. boost for three different fuel injection valves.

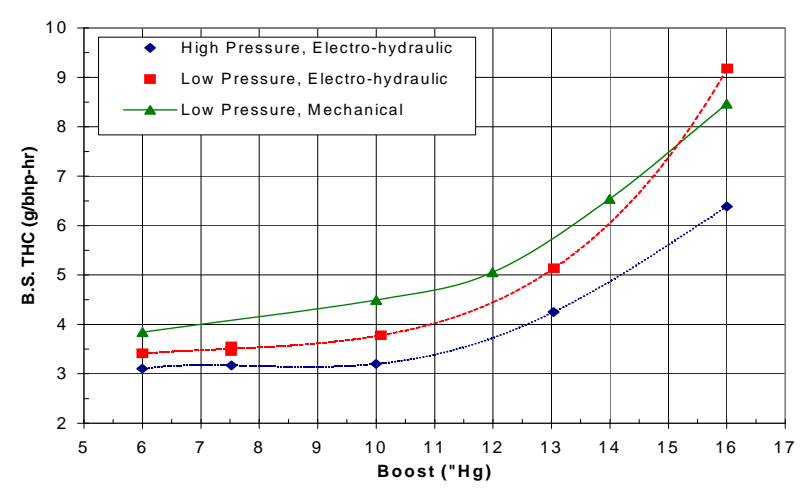

Figure 4. THC emissions vs. boost for three different fuel injection valves.

low pressure electro-hydraulic valve and the mechanical valve. This highlights an advantage of the low pressure electro-hydraulic valve. Other emissions, $\mathrm{CO}$ and $\mathrm{NO}_{\mathrm{X}}$ (not shown), also change with the implementation of high pressure electro-hydraulic injection. Emissions of CO are higher for high pressure electro-hydraulic for the same boost. It is interesting that $\mathrm{CO}$ and formaldehyde are both products of partial combustion, though high pressure shifts them in opposite directions. It indicates that formation mechanisms for formaldehyde and $\mathrm{CO}$ are different. Emissions of $\mathrm{NO}_{\mathrm{X}}$ are reduced with HPFI for the same boost. This is primarily due a reduction in fuel consumption for HPFI, resulting in a leaner air fuel ratio. $\mathrm{NO}_{\mathrm{X}}$ emission is generally reduced at leaner air fuel ratios due to lower in-cylinder temperatures.

Figures 5 and 6 plot Brake Specific Fuel Consumption (BSFC) and Coefficient of Variation (COV) of Peak Pressure (PP) vs. Boost. The fuel consumption reduction is evident. High pressure electro-hydraulic reduces fuel shown) are also reduced by PCC ignition. However,the reduction occurs primarily at high boost $>12$ " $\mathrm{Hg}$. consumption at all boost levels compared to low pressure mechanical and at most boost levels compared to low pressure electro-hydraulic. COV of PP is a measure of combustion instability. High pressure electro-hydraulic produces lower

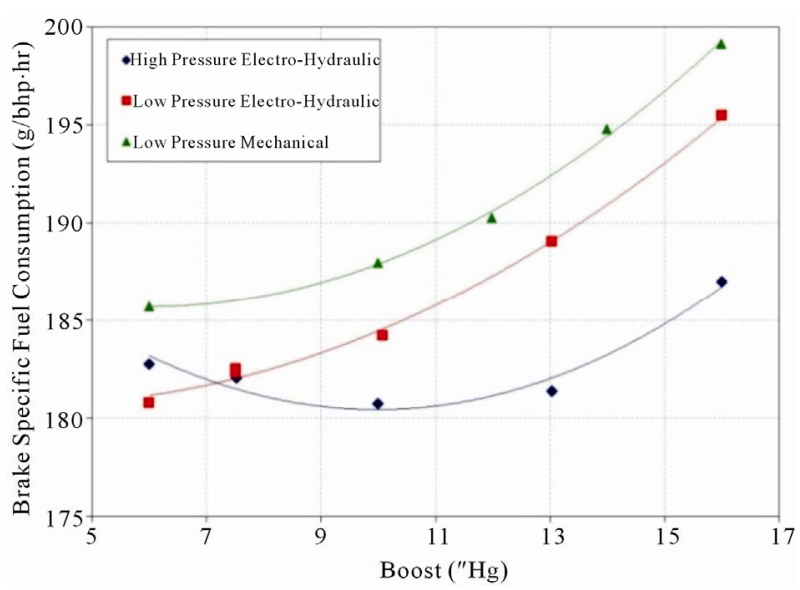

Figure 5. Brake specific fuel consumption vs. boost for three different fuel valves.

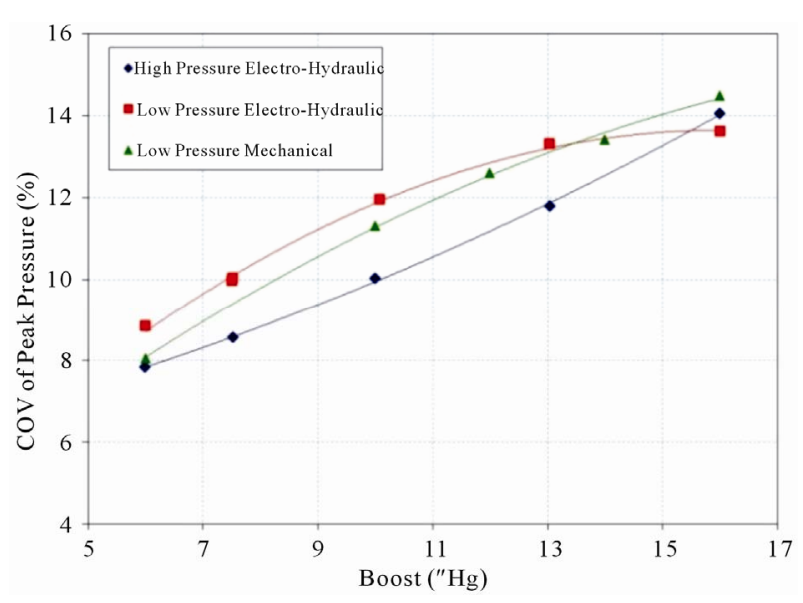

Figure 6. COV PP vs. Boost for three different fuel valves.

combustion instability (Figure 6) than the other two cases at most boost levels. This is due to improved mixing. Lower COV of PP represents an extension of lean limit of combustion, which allows additional $\mathrm{NO}_{\mathrm{X}}$ reductions to be realized.

Figure 7 shows how formaldehyde emissions change with various ignition sources, including a PCC. For most of the boost levels tested, the PCC shows a significant decrease in formaldehyde emissions. The difference between SS and MS is insignificant. In general enhanced ignition sources tend to stabilize combustion, reducing combustion variability. Although the PCC is characterized by a burning jet flowing into the main chamber, the impact on mixing is expected to be less than HPFI because the timing of PCC ignition is later in the cycle. The benefit of PCC on formaldehyde formation is likely due to the impact on combustion stability. The frequency of quenching due to partial combustion is reduced when combustion is stabilized.

The impact of PCC ignition on combustion stability is shown in Figure 8. The data shows a dramatic decrease in 


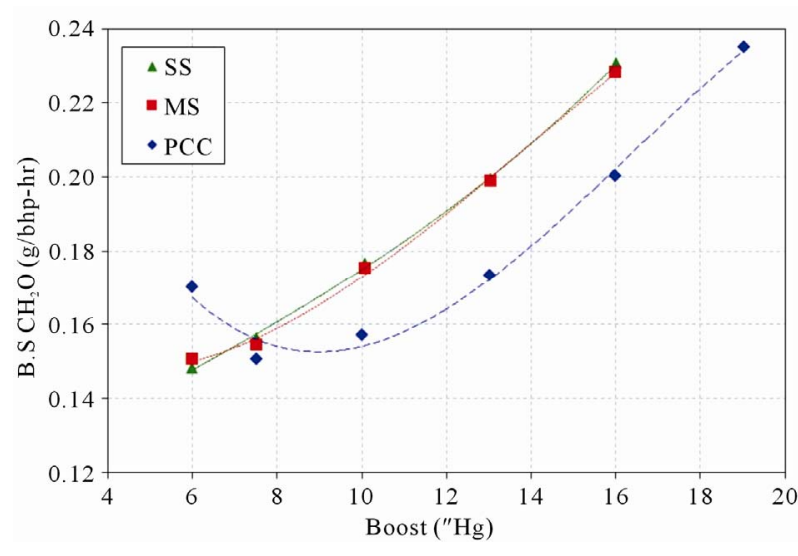

Figure 7. Formaldehyde emissions vs. Boost for three different ignition sources with low pressure electro-hydraulic fuel valves.

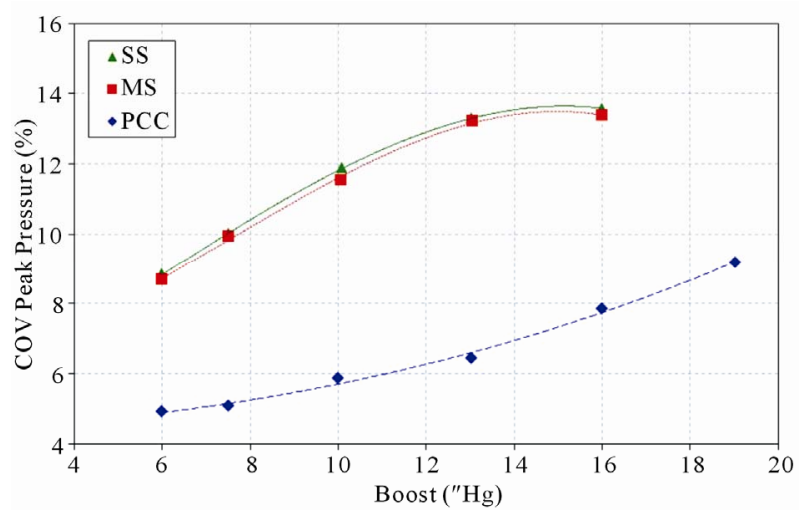

Figure 8. COV of Peak Pressure vs. Boost for three different ignition sources with low pressure electro-hydraulic fuel valves.

COV PP (increase in combustion stability) for PCC ignition. The COV of PP for a given boost is approximately reduced by half. THC emissions and brake specific fuel consumption (not shown) are also reduced by PCC ignition. However, the reduction occurs primarily at high boost $>$ 12 ” Hg.

\section{Discussion}

The data shows that HPFI and PCC ignition reduce formaldehyde significantly for the same engine operating parameters (speed, torque, and boost). These hardware changes physically impact mixing and combustion in such a way to reduce formaldehyde formation. The observed reductions in formaldehyde support mechanisms 1, 2, and 3 discussed in the Introduction. Reduction in formaldehyde is typically accompanied by a reduction in THC emissions. Three different modes are identified for formaldehyde reduction that can be related to HPFI and/or PCC ignition. They are described below.
The first mode of formaldehyde reduction is related to the reduction of the number of fuel rich regions in quench zones, such as crevice volumes. This mode is tied closely to HPFI. If the spread rate of the fuel jet is large enough fuel could flow directly into the top land crevice volume between the piston and cylinder, above the top ring. Previous visualization work using Planar Laser Induced Fluorescence (PLIF) [11,14] showed that the low pressure jet spreads and impinges directly on the top land crevice volume. Consequently fuel is forced into the top land crevice volume, creating a protected rich zone. However, the high pressure jet is narrow and impinges on the center of the piston with high velocity, creating a large scale motion that directs fuel upward and away from the top land crevice volume. HPFI tends to promote a uniform charge throughout the cylinder. This reduces THC emissions by eliminating regions of high fuel concentration. However, even with a homogeneous charge fuel resides in crevice regions characterized by the average trapped $\mathrm{A} / \mathrm{F}$ ratio. Many crevice regions have dimensions smaller than typical flame quench distances, so the flame is unable to propagate into the crevice and consume the resident fuel. This fuel can exit the crevice during expansion and be oxidized to formaldehyde.

The second mode of formaldehyde reduction involves turbulence that is present throughout the combustion process. The turbulence could be residual turbulence from high pressure injection or PCC jet induced turbulence. As combustion occurs in the cylinder, turbulence scavenges the unburned fuel and formaldehyde in the crevice volumes and mixes it with hot combustion gases, burning to completion.

The third mode of formaldehyde reduction involves more effective ignition. More effective ignition reduces partial combustion and misfire. A more uniform charge, created by HPFI, can be more reliably ignited since there are fewer regions outside the flammability range of the fuel. A distributed ignition source induced by the PCC jet achieves more reliable ignition in the lean main chamber because it is spatially distributed across the cylinder. It is not localized like a spark plug. Reduction of partial combustion through more reliable ignition reduces the impact of bulk quenching during expansion where formaldehyde can be formed.

\section{Conclusions}

The two techniques investigated as ways to augment mixing and combustion are HPFI and PCC ignition. Both are shown to be highly effective at reducing formaldehyde. Maximum reductions of about $15 \%$ are realized in both cases. HPFI improves mixing of fuel and air in the cylinder. This reduces fuel trapped in crevice volumes, creates a more homogeneous mixture, and stabilizes combustion. 
PCC ignition dramatically reduces COV PP by $50 \%$. This reduces formaldehyde formation in partial combustion zones. There is overlap in the modes by which formaldehyde is reduced for the two techniques. Therefore, formaldehyde reductions from HPFI and PCC ignition are not expected to be additive if the two techniques are combined.

\section{Acknowledgements}

This work was funded jointly by the Pipeline Research Counsel International and the Gas Technology Institute (formerly the Gas Research Institute). Gary Hutcherson and Jason Holden were instrumental in managing and executing the test programs. Numerous graduate and undergraduate students participated in the testing, including Dean Huntley, Kevin Johnson, and Stephanie Mick.

\section{References}

[1] G. S. Shareef, K. R. Ferry, M. Gundappa, C. A. Leatherwood, L. D. Ogle, L. M. Campbell, Gas Research Institute, "Measurement of Air Toxic Emissions from Natural Gas-Fired Internal Combustion Engines at Natural Gas Transmission and Storage Facilities,” Gas Research Institute, Amsterdam, 1996.

[2] L. F. Coerr, S. P. Coerr and S. L. Clowney, "EPA's Regulation of Air Toxic Emissions under the Industrial Combustion Coordinated Rulemaking (ICCR)," Proceedings of the 1998 Spring Technical Conference of the ASME Internal Combustion Engine Division, Vol. 1, Fort Lauderdale, 26-29 April 1998.

[3] D. B. Olsen and C. E. Mitchell, "Formaldehyde Formation in Large Bore Engines Part 2: Factors Affecting Measured $\mathrm{CH}_{2} \mathrm{O}$," Journal of Engineering for Gas Turbines and Power, Vol. 122, No. 4, 2000, pp. 611-616. doi:10.1115/1.1290586

[4] P. K. Kirschner, "Formaldehyde Emissions from Caterpillar 3600 Series Engines Utilizing Field Gas as Fuel,” Proceedings of the 1998 Spring Technical Conference of the ASME Internal Combustion Engine Division, Vol. 1, Fort Lauderdale, 26-29 April 1998.

[5] C. E. Mitchell and D. B. Olsen, "Formaldehyde Formation in Large Bore Natural Gas Engines Part 1: Formation Mechanisms," Journal of Engineering for Gas Turbines and Power, Vol. 122, No. 4, 2000, pp. 603-610. doi:10.1115/1.1290585

[6] D. B. Olsen, J. C. Holden, G. C. Hutcherson and B. D. Willson, "Formaldehyde Characterization Utilizing InCylinder Sampling in a Large Bore Natural Gas Engine,” Journal of Engineering for Gas Turbines and Power, Vol. 123, No. 3, 2001, pp. 669-676. doi:10.1115/1.1363601

[7] D. B. Olsen and B. D. Willson, "The Effect of Parametric Variations on Formaldehyde Emissions from a Large Bore Natural Gas Engine," Proceedings ASME-ICE Spring Technical Conference, ICE-Vol. 38, Paper No. 2002-ICE-446, Rockford, 2002.

[8] B. Willson, G. Hutcherson, S. Hawley and K. Willett, "Relative Performance of High-Pressure Fuel Gas Delivery on Large-Bore, Two-Stroke Natural Gas Engines," Gas Machinery Conference Proceedings, Austin, October 1997.

[9] B. Willson, G. Hutcherson, D. Olsen and J. Holden, "Evaluation of High Pressure Injection of Fuel Gas in Large-Bore Natural Gas Engines, Technical Report, GRI-99/0275, Gas Research Institute, Des Plaines, 1999.

[10] A. Kirkpatrick, Y. Li, C. Mitchell and B. Willson, “Analytical and Computational Modeling of High Pressure Gas Injection," Proceedings ASME ICE Fall Technical Conference, Vol. 37-2, Paper No. 2001-ICE-410, Argonne, 2001.

[11] D. B. Olsen, D. B. Mastbergen and B. D. Willson, "Planar Laser Induced Fluorescence Imaging of Gas Injection from Fuel Valves for Large Bore Natural Gas Engines," Proceedings ASME-ICE Fall Technical Conference, Vol. 37-2, Paper No. 2001-ICE-409, 2001.

[12] D. B. Olsen and J. M. Lisowski, "Prechamber NOx Formation in Low BMEP 2-Stroke Cycle Natural Gas Engines," Applied Thermal Engineering, Vol. 29, No. 4, 2009, pp. 687-694.

doi:10.1016/j.applthermaleng.2008.03.049

[13] D. B. Olsen andA.T. Kirkpatrick, "Experimental Examination of Prechamber Heat Release in a Large Bore Natural Gas Engine,” Journal of Engineering for Gas Turbines and Power, Vol. 130, No. 5, 2008, pp. 052802 052809. doi:10.1115/1.2906182

[14] D. B. Olsen and B. D. Willson, "The Impact of Cylinder Pressure on Fuel Jet Penetration and Mixing”, Proceedings ASME-ICE Fall Technical Conference, Vol. 39, New Orleans, 8-11 September 2002, pp. 233-239. 